\title{
AS INSTITUIÇÕES DO FEDERALISMO: COM RESPEITO A UM QUADRO ANALÍTICO ${ }^{1}$
}

DAVID E. WILDASIN ${ }^{\dagger}$

RESUMO: As federações amadurecidas apresentam relativa transparência quanto a delimitações de autoridade entre os níveis de governo, os governos subnacionais gozam de uma autonomia considerável em suas políticas de despesas, receitas e dívidas. Em outros países, os problemas de restrições orçamentárias suaves, resgates e instabilidade fiscal e financeira demonstram as dificuldades do desenho institucional de uma federação. Este artigo descreve um quadro analítico no qual os efeitos inter jurisdicionais ou jurisdicionais podem criar incentivos para governos de nível superior para intervir no controle e financiamento de governos de nível inferior ("resgates"). Essa estrutura ajuda a identificar orientações para pesquisas teóricas e empíricas que possam iluminar características importantes das instituições observadas e orientar a análise de políticas.

\footnotetext{
${ }^{1}$ Traduzido para o português, com a autorização do autor, por Maíra Almeida e revisado por Antonio Sepúlveda, do artigo de David Wildasin, originalmente publicado no National Tax Journal, Vol. LVII, No. 2, Parte 1, Junho de 2004 (2014), The Institutions of Federalism: Toward an Analytical Framework, produzido originalmente em língua inglesa. Maíra Almeida é Mestra e Doutoranda em Direito pelo Programa de Pós-Graduação em Direito da Universidade Federal do Rio de Janeiro (PPGD/UFRJ), pesquisadora visitante na Faculdade de Direito de Harvard, com apoio da CAPES e da Comissão Fulbright e membro do Laboratório de Estudos Institucionais (LETACI). Antonio Sepúlveda é Professor e Doutorando em Direito/UERJ. Pesquisador do Laboratório de Estudos Institucionais (LETACI).

+ Professor emérito de Economia da Martin School da Universidade de Kentucky, Lexington. E-mail: dew@davidwildasin.us.
} 


\section{INTRODUÇãO: As INSTITUIÇÕES DO FEDERALISMO}

Idealmente, as políticas fiscais dos governos estaduais e municipais e dos governos subnacionais nos países de todo o mundo devem permitirlhes fornecer bens e serviços públicos altamente valorizados aos seus residentes, financiados por sistemas de receita que impõem pouco desperdício por perdas de peso morto e que distribui o ônus das finanças públicas de forma não ofensiva aos princípios de justiça e equidade. Seria um erro alegar que a federação dos EUA, ou a de qualquer outro país, "resolveu" todos esses problemas de finanças públicas em um sistema federal.

Por padrões mais modestos, no entanto, o sistema de federalismo fiscal dos EUA se apresentou de forma razoavelmente adequada durante um extenso período histórico. Embora o equilíbrio das responsabilidades entre os governos nacional, estadual e municipal esteja mudando continuamente, cada nível de governo assumiu um papel importante na execução e financiamento de importantes funções do setor público. Por exemplo, os governos estaduais e municipais desempenharam papéis de liderança na educação pública, na aplicação da lei, na segurança pública e no transporte. Em algumas áreas da política, como a redistribuição de renda em espécie (como os programas AFDC/TANF, Medicaid), os governos subnacionais têm sido parceiros importantes do governo nacional, por meio de sistemas complexos e sempre em evolução de transferências e regulamentos fiscais intergovernamentais. Quaisquer que sejam as suas deficiências, os governos federal, estadual e municipal realizaram essas e outras funções importantes e satisfativas para que a grande e complexa economia dos EUA cresça e prospere durante um longo período de tempo. $\mathrm{O}$ mesmo pode ser dito dos sistemas federais em outros países desenvolvidos, como o Canadá, a Austrália e a Alemanha. Em algum nível básico, essas instituições demonstraram sua viabilidade: gozam de recursos para a sua manutenção e, no mínimo, não representaram impedimentos importantes para o desenvolvimento econômico bem-sucedido. Numa perspectiva mais otimista, tais instituições podem ter contribuído de forma importante para alocação de recursos eficiente e equitativo - prosperidade, crescimento e justiça - em alguns países.

A experiência de outras nações em todo o mundo sugere, no entanto, que encontrar estruturas de governança e finanças públicas viáveis, para não dizer otimizadas, podem ser uma tarefa difícil. Para citar apenas alguns exemplos notáveis, países tão importantes e diversos como a 
Rússia, a Índia, o Brasil, a África do Sul e a China estão lidando com questões de finanças subnacionais, relações fiscais intergovernamentais e estrutura de governança desde década passada, suscitando problemas econômicos, jurídicos, políticos, regionais e sociais interligados e difíceis ${ }^{2}$. Nesses e em muitos outros países, a reestruturação dos sistemas fiscais foi acompanhada de mudanças de grande escala, não só na política, mas também nas instituições fundamentais do governo, o que inclui alterações de constituições nacionais. $\mathrm{Na}$ Índia, por exemplo, os governos locais conhecidos como panchayats receberam responsabilidades largamente expandidas por emendas feitas à constituição indiana em 1993. Existem quase 250.000 dessas unidades governamentais, "o que torna esta a maior tentativa de descentralização do governo em todo no mundo"(RAJAMARAN, 2003, p. 01). Para atuar de forma efetiva, essas unidades de governo devem fornecer serviços públicos apropriados, em níveis adequados, com instrumentos próprios de finanças. Se isso acontecerá dependerá da atribuição e desenvolvimento de funções de despesas e instrumentos de receita entre diferentes níveis de governo, a estrutura de regulação e controle sob o qual os governos de nível inferior operam e, portanto, o grau de autonomia de receita e despesa de que gozam e sobre a implementação administrativa e jurídica dessas políticas fiscais e regulatórias. A gama de escolhas a serem feitas ao longo de todas essas dimensões é imensa, e parte da tarefa que enfrenta a India, como outros países envolvidos em transformações similares, é projetar e

2 Esta pequena lista poderia ser ampliada facilmente, para incluir a maioria das economias em desenvolvimento e em transição do mundo. As referências à crescente literatura sobre este assunto poderiam facilmente preencher muitas páginas, inevitavelmente omitido contribuições importantes. Os leitores interessados podem consultar vários volumes editados - Bird et al. (1995), Martinez-Vasquez e Alm (2003), e Rodden et al. (2003) - para uma valiosa amostra de análises que lidam com muitos países individuais com muitas referências a literatura relacionada. Mais alguns estudos são citados abaixo. Os leitores também podem consultar Bahl e Wallich (1992) (China), Bahl (1995) (China e Rússia), o Banco Mundial (1995), Buckley e Mini (2000) (Rússia), (China), Wildasin (1992). ) e Ahmad (1997) (África do Sul). A descentralização fiscal e as estruturas institucionais das federações também são tema de debate em várias economias avançadas; para uma série de análises dos países escandinavos, ver Rattso (1998). Garcia-Mila et al. (2002), analisa o empréstimo do governo subnacional em antecipação a futuras transferências fiscais, com uma aplicação para dados em espanhol. Seitz (1999) e Rodden (2000) examinam resgates na Alemanha. Similar em espírito ao presente trabalho, Oates (2004) enfatiza a importância dessas questões e o desenvolvimento de uma teoria da "segunda geração" do federalismo fiscal. 
implementar uma estrutura institucional apropriada. Assim como as instituições do governo estadual e municipal têm sido importantes para o desempenho econômico de países como os EUA, muitos analistas chamam a atenção crescente para o papel das instituições na inibição do desenvolvimento econômico nos países pobres do mundo (ver, por exemplo, Easterly (2001)). As questões em jogo na compreensão das estruturas financeiras e de governança das federações são profundas.

A literatura existente sobre o federalismo fiscal pode esclarecer essas matérias complexas. Ao mesmo tempo, deve ser reconhecido que grande parte da pesquisa acadêmica sobre o financiamento do governo subnacional (aqui interpretada amplamente para englobar não só os sistemas de revenda (própria fonte) desses governos, mas a atribuição de serviços públicos, as responsabilidades de entrega para (e entre) elas, bem como as muitas formas de transações fiscais e mecanismos regulatórios que determinam as relações fiscais entre governos de nível superior e inferior) se concentraram, explicitamente ou implicitamente, nas federações dos EUA e do Canadá, o que se fundamenta em grande medida por seus parâmetros institucionais. Isso é mais evidente na literatura empírica do sujeito, que por sua natureza examina os dados e políticas de jurisdições particulares. As análises teóricas não são, em princípio, restritas à aplicação em períodos e lugares particulares, mas a pesquisa teórica aplicada baseia-se inevitavelmente em pressuposições, possivelmente implícitas, que podem ser bastante apropriadas em alguns contextos, mas inadequadas em outros. Nos Estados Unidos, no Canadá e em outras federações maduras, o status e o papel fundamentais dos governos subnacionais - a existência e os limites dos Estados NorteAmericanos ou das províncias canadenses, o status legalmente inferior de seus estatutos, leis e regulamentos para o país e a constituição, a definição básica das esferas legítimas da autoridade fiscal e de despesa para cada nível de governo e o grau de autonomia de que gozam - foi amplamente resolvida. Nos Estados Unidos, nenhum movimento de secessão grave surgiu desde a década de 1860, os estados e as localidades geralmente não obstruem a aplicação da lei federal dentro de seus limites e os impostos estaduais e municipais em uso generalizado foram testados em disputas legais e, como regra geral, foram encontrados dentro dos legítimos poderes de tributação concedidos a eles sob a Constituição dos EUA. As estruturas administrativas e de execução evoluíram para implementar as políticas fiscais desses governos e para facilitar sua 
coordenação ${ }^{3}$. Essas e uma série de outras características das estruturas institucionais das federações maduras evoluíram por longos períodos de tempo e, de fato, sua evolução é infinita. Mas elas são relativamente estáveis e fornecem um pano de fundo para a análise das finanças governamentais estaduais e municipais e das relações fiscais intergovernamentais que fundamentam a literatura do sujeito, como representado, por exemplo, pelo Federalismo clássico de Oates (1972) e todos os livros didáticos modernos sobre o assunto.

Há, então, a necessidade de investigar mais detalhadamente a estrutura institucional da governança e das finanças públicas nos sistemas federais. Quais são as instituições essenciais das federações maduras? Como elas facilitam a descentralização fiscal efetiva, em que os governos subnacionais podem desfrutar de despesas substanciais, receita e autonomia de empréstimos, evitando políticas fiscais disfuncionais que os levariam a sofrer dificuldades financeiras? A discussão abaixo destinase a contribuir para uma perspectiva analítica que pode ser útil para entender por que e em que condições as relações institucionais entre os governos conduzem a crises fiscais e financeiras e em que condições esses resultados podem ser evitados.

A próxima seção destaca alguns aspectos das experiências fiscais e financeiras das federações nos EUA e em outros lugares. Esta discussão enfatiza que, em alguns casos, os governos subnacionais, como os dos EUA, emprestam de forma ampla e são receptores de transferências fiscais em larga escala de governos de nível superior e, no entanto, parecem operar de forma financeira ordenada - de forma responsável, enquanto as políticas financeiras e fiscais em outros casos podem levar a grandes crises financeiras e fiscais. A terceira seção apresenta um modelo teórico simples que se concentra em externalidades como determinantes fundamentais das relações fiscais entre os governos. Às vezes, como na teoria tradicional do federalismo fiscal, esse modelo sugere que as transferências fiscais intergovernamentais (sob a forma de subsídios de correspondência) podem assegurar a provisão eficiente de bens e serviços públicos produtores de externalização, preservando a autonomia local e a descentralização fiscal efetiva. Em outros casos, no entanto, o modelo sugere que os governos de nível inferior podem ter incentivos para agir

3 Para oferecer apenas uma ilustração: os governos estaduais e municipais frequentemente implementam impostos sobre indivíduos e operações que se baseiam em grande parte em impostos federais similares. A aplicação desses impostos subnacionais é fortemente facilitada pela divisão de informações entre autoridades fiscais em diferentes níveis de governo. 
de forma contrária a interesses sociais mais amplos e, ao fazê-lo, desencadear intervenções em assuntos locais (perda de autonomia local) por nível superior governos. Nesses casos, a provisão de serviços públicos totalmente eficiente pode não ser alcançável e a centralização fiscal é um resultado possível. Esse quadro teórico identifica, portanto as condições em que as instituições de descentralização fiscal podem ser viáveis e as condições em que elas são susceptíveis de se arruinar- em última análise, talvez, ser substituída por acordos mais centralizados.

A quarta seção analisa algumas das possíveis implicações da presente análise para duas questões relacionadas: a atribuição de responsabilidades de despesa a diferentes níveis de governo em uma federação e a determinação da estrutura intergovernamental da dívida. A quinta seção discute algumas outras questões teóricas e empíricas pendentes que aguardam uma análise mais aprofundada. A última seção conclui.

\section{CRISE FisCAL LOCAL: "INCIDENTES CURIOSOS" NO FEDERALISMO AMERICANO}

Recentemente, muitos autores evidenciam os problemas potenciais associados aos empréstimos por governos subnacionais (por exemplo, Prud'homme (1995), Tanzi (1996) e Ter-Minasian (1996)). Em resumo, a preocupação básica é que esses governos podem pedir empréstimos excessivamente, dependendo do financiamento da dívida, quando eles deveriam estar cobrando impostos, gastos em projetos com desperdício ou com excesso de pessoal e compensação para funcionários do governo e, eventualmente, se tornando financeiramente insolvente, criando interrupções em mercados de capitais e possivelmente colocando em risco a estabilidade de todo o sistema financeiro. O empréstimo excessivo por governos subnacionais também pode aumentar a pressão sobre os bancos centrais para expandir o crédito e o fornecimento de dinheiro excessivamente, criando pressões inflacionárias e ameaçando a estabilidade macroeconômica geral ${ }^{4}$.

\footnotetext{
${ }^{4}$ Esta preocupação é evidente em algumas das análises realizadas por instituições como o Banco Mundial e o Fundo Monetário Internacional. É fácil entender por que os credores devem se preocupar com a credibilidade dos mutuários, especialmente à luz das periódicas "crises da dívida" que prejudicaram os países em desenvolvimento e seus credores (vide Easterly (2001) para uma discussão informativa sobre os ciclos de dívida em países menos desenvolvidos). No entanto, há um paradoxo - um
} 
Como qualquer devedor, os governos estaduais ou locais americanos podem, às vezes, encontrar-se incapazes de fazer pagamentos obrigatórios a credores, vendedores e outros. Em tais situações, eles podem recorrer a processos de falência nos termos do Capítulo 9 da Lei Federal de Falências. Na prática, no entanto, quase nenhum governo atravessa processos de falência. ${ }^{5}$ Isso não quer dizer que os governos subnacionais nos EUA nunca experimentem o dissabor fiscal. Nova York, Filadélfia, Washington DC e Orange County, Califórnia, passaram por episódios de insolvência ameaçada, se não real. No momento da escrita do presente artigo, a cidade de Pittsburgh se encontra em circunstâncias semelhantes, enquanto o Estado da Califórnia está lidando com obrigações de dívida maciças. ${ }^{6}$ No entanto, as crises fiscais estaduais ou locais são "incidentes curiosos" na experiência dos EUA, exceções à regra geral. ${ }^{7}$ Mas por qual razão? Em parte, deve ser porque esses governos geralmente agem com "restrição fiscal", o que significa que eles seguem políticas que geralmente não levam a processos de falência. Em parte, é também devido às ações de governos superiores que, por meio de suas próprias políticas fiscais e regulatórias, criam um ambiente que induz as políticas fiscais "apropriadas" por governos inferiores ou que os resgata de políticas "inapropriadas" antes da falência. Quais os incentivos que

interessante - quando os credores são incomodados por mutuários que desejam emprestar. Afinal, uma solução para o problema do empréstimo "excessivo" é que os credores saibam do negócio de empréstimos. É instrutivo contemplar por que esta não é a melhor solução e a mais simples para o problema do controle do endividamento dos países em desenvolvimento, como os "países em desenvolvimento altamente endividados" que foram foco de atenção muito recente.

${ }^{5}$ Desde 1937, quando as leis de falência atuais foram promulgadas, houve apenas cerca de 500 pedidos de falência por parte dos governos locais, um pequeno número, já que quase 100 mil governos locais nos EUA. Vide o Escritório Administrativo dos Tribunais dos Estados Unidos (2000a, b, Tabela F-2)) e a Comissão Nacional de Revisão de Falências (1997) para discussão e dados adicionais.

${ }^{6}$ Durante a crise fiscal de Washington DC na década de 1990, o General Accounting Office (GAO) (1995) realizou uma série de estudos de caso de grandes cidades dos EUA que haviam entrado em alguma forma de administração judicial. Vide Holloway (1996a, 1996b) para alguns resumos das descobertas. Para a atual experiência de Pittsburgh, Vide Strauss (2003).

${ }^{7}$ Na famosa história "Silver Blaze", Sherlock Holmes chama a atenção para o "incidente curioso" do cachorro na noite. O inspetor observa que o cão não fez nada na noite e Holmes afirma: "Esse foi o incidente curioso". 
alcançam os decisores, tanto nos governos inferiores como nos superiores, que induzem "restrição fiscal" por parte do primeiro?

Uma possibilidade é que o empréstimo por estados e localidades seja tão limitado, talvez por constituições estaduais ou por restrições regulatórias impostas pelos governos de nível superior, para reduzir sua exposição financeira a níveis inconsequentes. De fato, vários autores (como, por exemplo, von Hagen (1991), Poterba (1994) e Bohn e Inman (1996) descobriram que tais restrições têm um impacto significativo nas políticas fiscais subnacionais. Vale ressaltar, no entanto, que essas restrições certamente não proíbem que os governos subnacionais contraiam empréstimos. Pelo contrário, os governos subnacionais nos EUA realizaram empréstimos com entusiasmo. Por exemplo, em 2003, o estoque total de dívidas governamentais estaduais e locais e outros passivos (mesmo excluindo as obrigações dos fundos de aposentadoria) totalizaram aproximadamente US\$ 2,4 trilhões (Conselho de Governadores do Sistema de Reembolso Federal, 2004, Tabela L. 105), um valor que pode ser comparado com US\$ 4,9 trilhões de dívida pública do governo federal. Apesar desta grande quantidade de dívida pendente, os governos subnacionais como um todo são bastante solventes. $\mathrm{O}$ acesso aos mercados de capitais é claramente um elemento central no financiamento subnacional do governo nos EUA, o que, evidentemente, estabeleceu uma estrutura institucional dentro da qual os governos subnacionais gozam dos benefícios de tal acesso sem pôr em perigo a sua própria solvência, muito menos a estabilidade financeira geral da Economia dos EUA. ${ }^{8}$

\footnotetext{
8 As restrições constitucionais e outras sobre os governos subnacionais nos EUA claramente não resultaram em um baixo nível de empréstimo, o que sugere que eles operam de forma muito mais sutil do que uma simples proibição geral de empréstimos, por exemplo. De fato, essa proibição poderia simplesmente encorajar esses governos a expandir o uso de mecanismos de financiamento alternativos como a dívida. Por exemplo, uma cidade pode contratar trabalhadores com salários baixos, prometendo generosos benefícios de aposentadoria. Se não financiar adequadamente essas obrigações, ele muda o ônus da provisão de serviços atuais para os contribuintes futuros (ver, por exemplo, Epple e Schipper (1981), Inman (1981)) - um resultado financeiro que poderia ser alcançado de forma mais transparente através de empréstimos explícitos. Mecanismos semelhantes para a reatribuição intertemporal dos encargos e benefícios fiscais, incluem o diferimento das despesas de capital para a manutenção da infraestrutura (mantendo os carros da polícia em condições úteis, cortando as árvores para que a energia elétrica não seja interrompida pela queda de
} 
Se a experiência Norte-Americana ilustra como os governos subnacionais podem ter acesso aos mercados de capitais, evitando as catástrofes financeiras, a experiência de alguns outros países apresenta motivos para cautela. Na Argentina e no Brasil, os avanços conquistados em uma longa batalha contra a alta inflação e a instabilidade monetária parecem ter sido prejudicados pelos empréstimos do governo estadual e provincial. A participação do governo estadual no setor financeiro, especialmente através da propriedade dos principais bancos comerciais, facilitou a emissão de dívidas do Estado a grandes bancos cujo padrão prejudicaria potencialmente todo o sistema financeiro, criando fortes pressões sobre as políticas fiscais e monetárias do governo central. As autoridades absorvem e monetizam a dívida do governo subnacional. ${ }^{9}$ $\mathrm{Na}$ China, os desequilíbrios fiscais surgiram como consequência de reformas econômicas rápidas (um afrouxamento de restrições de planejamento do governo central e menor dependência de empresas estatais em financiar e prestar serviços públicos), juntamente com sistemas de receita pouco desenvolvidos para os governos locais e provinciais e, em alguns casos, demandas urgentes de despesa pública associadas ao rápido desenvolvimento econômico e a grandes mudanças demográficas. Nessas circunstâncias, os governos subnacionais podem enfrentar incentivos que levem a empréstimos excessivos (e muitas vezes implícitos) (Qian e Weingast, 1996; e Jin e Zou, 2003). Na Índia, as relações fiscais do Estado central, incluindo sistemas complexos de bolsas

membros durante o mau tempo) ou entrando contratos de longo prazo com fornecedores. Quaisquer que sejam os riscos financeiros associados a empréstimos locais explícitos, existem riscos similares associados a tais empréstimos implícitos. Restrições regulamentares que limitam o primeiro, mas não o último, podem reduzir a transparência dos empréstimos locais, mas não necessariamente o seu montante; eles também podem resultar em custos de empréstimos efetivos mais elevados (no saldo, pode ser menos dispendioso emitir dívidas e manter as árvores cortadas ou os buracos reparados do que permitir que a infraestrutura se deteriore). A magnitude das obrigações implícitas do governo estadual e local nos EUA é difícil de estimar, mas deve ser reduzida pelos trilhões de dólares de passivos não financiados do governo federal (especialmente as obrigações de segurança social). Vide Kotlikoff (1992) e Auerbach et al. (1999) para mais discussão sobre essas questões.

9 Vide Dillinger e Webb (1999), Webb (2003) e Rodden (2003). Saiegh e Tommasi (1998) se concentram nos custos de transações como um fator importante no desempenho institucional na Argentina, que, conforme detalhado por Hart (1995), pode ser contrastado com contratos incompletos; a abordagem analítica esboçada abaixo é talvez melhor caracterizada nos termos do último, e não do primeiro. 
intergovernamentais e concessão de empréstimos, foram alvo de recentes esforços de reforma. Aparentemente, o endividamento do governo estadual cresceu à medida que as transferências implícitas do governo central aos governos estaduais foram restringidas (Mc-Carten, 2003), sugerindo que o empréstimo pelos governos subnacionais pode não ser facilmente controlável.

O termo "restrição de orçamento flexível" é freqüentemente usado para se referir a fenômenos desse tipo. Em cada um dos casos que acabamos de mencionar, parece que as políticas fiscais prosseguidas pelos governos subnacionais podem criar riscos financeiros, primeiro para si próprios e, em segundo lugar, para os governos de alto nível que podem acabar tendo que "resgatá-las". Os governos subnacionais podem ter incentivos fracos para conduzir suas políticas fiscais de forma a minimizar o risco de resgates. Um sistema de governo descentralizado que dá origem a finanças desordenadas para governos de nível inferior, impõe riscos financeiros ao resto da sociedade, desencadeia um endividamento excessivo para toda a nação e pode até ameaçar a estabilidade monetária, dificilmente é adequado para a provisão eficiente de serviços públicos, políticas orçamentais equitativas e desenvolvimento econômico. Por que alguns países parecem enfrentar problemas com restrições orçamentárias suaves para governos subnacionais, enquanto que, na experiência dos EUA, essas dificuldades parecem ser bastante raras?

Por óbvio, não há uma resposta simples a esta questão, uma vez que as circunstâncias de diferentes países variam de forma ampla. Além disso, o estudo sério do problema das restrições orçamentais suaves apresenta uma dificuldade imediata: como podemos até definir "restrições orçamentárias suaves" ou "resgates" em um sentido significativo? As transferências fiscais intergovernamentais explícitas são uma característica de longa data e importante do sistema federal dos EUA. O mesmo acontece com outras federações, como Canadá, Alemanha, Brasil e Índia. No caso dos EUA, as subvenções explícitas do governo federal aos governos estaduais e locais em 2002 totalizaram cerca de US \$ 351 bilhões, cerca de 3,4\% do PIB e cerca de 17,5\% do total das despesas federais (Office of management and Budget - OMB, 2004b, Tabela 12.1). Se as transferências fiscais intergovernamentais por si só constituem "resgates", então a federação dos EUA foi transportada com resgates por décadas. Além de transferências intergovernamentais explícitas, os governos nacionais às vezes fazem transferências implícitas significativas para governos de nível inferior. No caso dos EUA, a 
dedução de quantidades significativas de impostos estaduais e locais de acordo com o imposto de renda federal fornece uma forma de transferência implícita, enquanto a isenção do imposto de renda sobre o interesse na dívida do governo estadual e local é outra. As estimativas de despesas tributárias do Office of management and Budget (OMB, 2004a, Tabela 18-1) para esses dois itens para 2003 são de cerca de US \$25,5 bilhões e US $\$ 49,6$ bilhões, respectivamente. Mesmo a dedutibilidade dos impostos sobre a renda da despesa de juros de hipoteca e outras políticas federais que estimulam o investimento em habitação residencial têm o efeito de aumentar o tamanho da base do imposto de propriedade real de que dependem muitos governos locais e, portanto, pode indiretamente apoiar as finanças de governos subnacionais.

Esses altos níveis de transferências fiscais explícitas e implícitas para governos de nível inferior significam, afinal, que os governos subnacionais nos EUA enfrentam restrições orçamentárias suaves? Os governos estaduais e locais certamente enfrentarão uma angústia fiscal significativa se essas transferências fossem eliminadas de forma inesperada. Eles podem tentar compensar o déficit de receita por empréstimo. $\mathrm{O}$ empréstimo do governo estadual e local era de cerca de US \$ 46 bilhões em 2002, enquanto suas despesas totais eram de cerca de US \$ 1.040 bilhões. O empréstimo do governo federal nesse ano foi de cerca de US \$ 317 bilhões. Visto de uma perspectiva completamente estática, o cancelamento das subvenções federais aos governos subnacionais teria transformado as contas federais do déficit em superávit e teria aumentado drasticamente os déficits deste último, talvez ao ponto de insustentabilidade. Nesse sentido, as atuais transferências federais protegem os governos subnacionais das consequências de políticas fiscais de outra forma insustentáveis. Se as transferências intergovernamentais encontradas no sistema fiscal dos EUA não constituem resgates, como, exatamente, os "resgates" devem ser definidos?

A mera existência de transferências intergovernamentais não parece capturar a noção intuitiva de "resgates", que de alguma forma deve refletir transferências "irregulares" ou "extranormais", talvez "necessárias" pela insinuação financeira "iminente" de governos de menores níveis. Mesmo essa definição parece perder o elemento crucial dos incentivos perversos, incurso, no entanto, por restrições orçamentárias "suaves". Os governos subnacionais podem experimentar desequilíbrios ou crises fiscais decorrentes de uma ampla gama de causas. As perdas de desastres naturais, como terremotos, inundações, secas ou furacões, podem afetar tanto a demanda por gastos públicos, 
quanto a reconstrução da infraestrutura danificada, por exemplo, e por meio da interrupção da atividade econômica e da destruição de recursos valiosos, a capacidade de receita das jurisdições afetadas. As transferências extraordinárias de um governo nacional para uma jurisdição subnacional que sofreu alguma catástrofe natural podem ser caracterizadas como a execução de um contrato de seguro social implícito ao invés de um resgate que reflete poucas escolhas fiscais por um governo de nível inferior que antecipe um resgate. (Vide Bucovetsky (1997), Bordignon et al. (2001) e referências para a discussão das transferências intergovernamentais como forma de seguro, o que enfatiza especialmente a importância das assimetrias informativas para uma política ótima.) $\mathrm{O}$ mesmo poderia seja dito sobre transferências fiscais extraordinárias decorrentes de catástrofes causadas pelo homem, como os ataques terroristas de setembro de 2001 (WILDASIN, 2002).

Embora essas observações sejam desprovidas de formalidade, elas sugerem que uma restrição orçamentária "suave" deve, de alguma forma, refletir uma desvantagem das relações fiscais "normais" que é a consequência, pelo menos em parte, do exercício da discrição por parte dos governos de nível menor. Existe também uma forte presunção de que esse comportamento é uma resposta aos incentivos implícitos oferecidos por um governo de nível superior e que as decisões tomadas por governos de nível inferior que enfrentam restrições de orçamento suaves são de alguma forma "prejudiciais para a sociedade". Essas ideias exigem alguma formalização, especialmente se elas devem ser operacionalizados para pesquisa empírica e orientação significativa na formulação de políticas.

\section{RESTRIÇÕES ORÇAMENTÁRIAS DURAS E SUAVES: UM QUADRO ANALÍTICO}

Para demonstrar essas ideias com um foco analítico mais nítido, consideremos a situação clássica do "livro de casos" em que uma localidade oferece um serviço público aos seus moradores que podem produzir benefícios externos para outros na sociedade. A estrutura de efeitos benéficos é natural para a análise de resgates ou, mais geralmente, de intervenções de governos de nível superior nos assuntos fiscais de governos subordinados; tais intervenções são difíceis de explicar se as decisões deste último não são importantes, de alguma forma, para o resto 
da sociedade, cujos interesses são representados pelo governo de nível superior. ${ }^{10}$

Para evitar complicações desnecessárias, suponha, agora, que todos os indivíduos na localidade tenham preferências e rendimentos idênticos e que a localidade possa financiar suas despesas utilizando um imposto local fixo ideal. Se x denota a quantidade de consumo privado de um residente típico local, e a renda do agregado familiar e a quantidade de gastos no serviço público local, a restrição de orçamento AB na Figura 1 mostra o menu de opções disponíveis para os residentes da localidade se eles agir em isenção de um governo de nível superior: os recursos disponíveis para a localidade podem ser inteiramente gastos em bens privados (ponto A) ou, por meio de impostos locais, em parte ou no total (ponto B) no local serviços públicos. Com preferências locais convexas, algum ponto dessa restrição seria o ponto de vista preferido dos residentes locais. Neste ponto, a taxa marginal de substituição dos residentes locais entre o consumo privado e o bem público local, MRSlxz, seria igual a 1 . Se o serviço público local beneficiar apenas os residentes locais, esse resultado é eficiente. Se o serviço público local produzir benefícios de derrames, no entanto, a tomada de decisão local produzirá um resultado ineficiente.

\footnotetext{
${ }^{10}$ Um modelo semelhante é desenvolvido com maior formalidade por Wildasin (1997). A presente análise generaliza algumas das ideias-chave desse documento. Os leitores também devem consultar Inman (2003) para uma discussão perspicaz e abrangente sobre a experiência dos EUA que enfatiza o papel dos mercados financeiros, as questões de credibilidade e construção da reputação e outras considerações que complementam a presente discussão.
} 


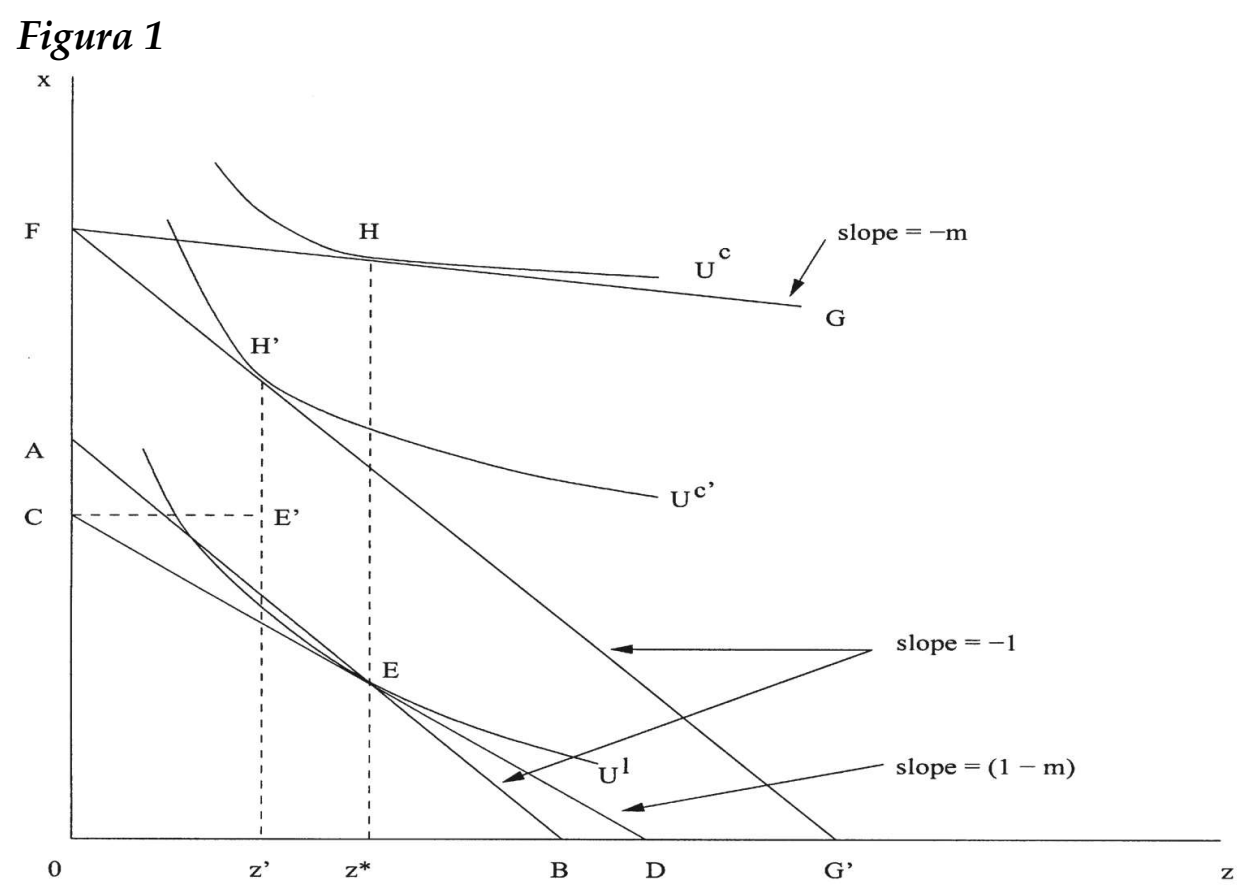

Os subsídios de correspondência fornecidos por um governo de nível superior (denotado por um sobrescrito $c$, como "central") são o remédio clássico para as ineficiências associadas aos efeitos benéficos. Essas subvenções devem, naturalmente, ser financiadas com impostos cobrados pelo governo de nível superior. Supondo que o governo de nível superior também seja capaz de cobrar receita de forma fixa, com o valor desse imposto denotado pela $T^{c}$, o efeito de uma política de correspondência é representada por uma mudança da restrição orçamentária da comunidade local como está demonstrado em $C D$ na Figura 1. O total de recursos disponíveis para os residentes locais é reduzido para $I-T^{c}$ devido aos impostos coletados no nível superior e o preço relativo dos serviços públicos locais é reduzido para (1- $m$ ) onde $m$ ( a "taxa de correspondência") denota a fração das despesas locais financiadas pelo governo de nível superior. Se a taxa de correspondência for escolhida corretamente, induzirá a localidade a escolher um nível de gasto local que reflita os benefícios dos serviços públicos locais para toda a sociedade, incluindo não apenas os residentes locais, mas os que residem fora da localidade. Deixar a $M R S^{c}{ }_{x z}$ indicar a taxa de substituição marginal dos não residentes entre os particulares, o consumo e os serviços 
públicos da localidade, ou seja, a avaliação marginal que os não residentes colocam nesses serviços, um nível eficiente de serviços locais z * ocorre onde $M R S_{x z}+M R S_{x z}=1 . m=M R S^{c} x z$ é uma taxa de correspondência ótima, conforme ilustrado na Figura 1, pode-se induzir (ou apoiar) a provisão de serviços públicos localmente melhorada, internalizando o efeitos benéficos. Observe que a taxa de correspondência ótima reflete a magnitude dos efeitos benéficos na margem; a taxa de correspondência é pequena se esses efeitos forem pequenos na margem, mesmo que unidades inframarginais de serviços públicos produzam grandes efeitos.

Para mostrar a situação das famílias não residentes (representativas), suponha que o ponto $F$ na Figura 1 represente o rendimento que estará disponível para consumo se não houver uma concessão correspondente disponível para a localidade. A linha $F G$, que tem uma inclinação de $-m$, ilustra que uma concessão de correspondência para a determinada localidade impõe um fardo ao resto da sociedade, sob a forma de impostos pagos ao governo de nível superior para financiar essa concessão. Quando a localidade fornece $z$ * unidades de serviços públicos, os não residentes gozam do benefício externo derivado desses serviços, mas também devem sacrificar algum bom consumo privado, como mostra o ponto $H$, devido aos impostos que pagam ao nível superior governo. Conforme mostrado pela curva de indiferença $U^{c}$ na Figura 1, os não residentes estão em equilíbrio melhor neste ponto do que seria o caso no ponto $\mathrm{F}$, onde $z=0$.

Nesta análise, os subsídios de correspondência servem como subsídios corretivos pigouvianos. Implicitamente, o governo de nível superior atua como uma espécie de líder Stackelberg, "anunciando" uma política de concessão de correspondência a qual os governos locais reagem, tomando essa política como parâmetro. Essa análise líderseguidor é plausível em um ambiente em que existem muitos governos locais e um quadro político estabelecido pelo governo de nível superior que aplica a todas as localidades - um programa de apoio estatal com base em fórmulas de apoio financeiro para muitos. Uma série de distritos escolares locais pode ser uma boa ilustração. A análise não permite a possibilidade, no entanto, de que o menu de escolhas sugerido pela política de concessão de correspondência do centro - o $C D$ de restrição de transferência - pode, no entanto, ser "admissível" no sentido de que o centro não desejaria necessariamente agir de acordo com essa política em todas as circunstâncias. Em particular, suponha que a localidade, em vez de escolher o nível eficiente de serviços públicos $z^{*}$, reduza seus impostos e gastos locais - para exemplo, a 0. Essa escolha parece irracional, uma 
vez que o pacote de consumo em $C$ é pior, do ponto de vista dos residentes locais, do que $\left(x^{*}, z^{*}\right)$. Conforme mencionado acima, no entanto, também é pior do ponto de vista dos não residentes: a subprovisão de um serviço público externo que prejudica os interesses dos estrangeiros. A título de ilustração, o caso de $z=0$ pode representar uma situação em que os veículos da polícia já não funcionam, prejudicando a segurança pública, não só para os residentes locais, mas para turistas ou passageiros, ou onde a manutenção insuficiente das instalações locais de tratamento de água coloca em risco não apenas a qualidade do abastecimento local de água, mas de infraestrutura pública compartilhada com outras jurisdições e a qualidade da água consumida por não residentes que extraem água da mesma fonte. ${ }^{11}$

Embora a falta de prestação de serviços públicos locais possa prejudicar os residentes locais, também pode induzir uma resposta do nível superior do governo para garantir pelo menos um nível mínimo de prestação de serviço público, se por nenhuma outra razão além de proteger o interesse de não residentes. Se o nível superior do governo fornecer diretamente o bem público local, com o custo total, o consumo de não residentes ficará na linha do orçamento FG, com uma inclinação de -1. Alternativamente e, em termos de diagrama, de forma equivalente, o nível superior do governo pode assumir o controle de algumas funções de governo local e injetar fundos suficientes ao financiamento dessas funções para que o governo local pague o nível de serviço público o mais alto as autoridades desejam. Do ponto de vista dos não residentes, o melhor resultado nesta linha está em $\mathrm{H}^{\prime}$, correspondendo a um nível $\mathrm{z}$ de prestação de serviços públicos locais. Esse nível de provisão não é socialmente eficiente e pode representar um nível mais baixo de serviços públicos do que os residentes locais prefeririam, não apenas no âmbito do programa de correspondência, mas inclusive na ausência de tal programa. No entanto, os residentes locais ainda podem preferir esse resultado para a alocação socialmente eficiente $\left(x^{*}, z^{*}\right)$ - não porque eles

\footnotetext{
${ }^{11}$ Durante a crise fiscal do Washington DC no início da década de 1990, os relatórios da imprensa local indicaram que os detetives de homicídios foram reduzidos a usar o transporte de ônibus da cidade por falta de automóveis no departamento de polícia, que a polícia do Capitólio estava oferecendo pneus usados para a polícia de DC e que uma importante instalação de tratamento de água no rio Potomac, cujo custo deveria ser compartilhado pelo Distrito e os Estados da Virgínia e Maryland, estava em mau funcionamento e sofreu danos porque o Distrito não aderiu aos compromissos de manter a instalação .
} 
gostem de um nível mais baixo de serviços públicos locais, mas porque eles podem se livrar das despesas feitas pelo governo de mais alto nível, segundo o qual eles ainda gozam de serviços públicos a zero custo local. Dado que as despesas locais caíram para zero, pelo menos para esse serviço público em particular, os residentes locais poderão consumir unidades $\mathrm{C}$ de consumo privado; com o governo de nível superior que fornece unidades $\mathrm{z}$ do serviço público local, o consumo final de residentes locais ocorre no ponto E '. Conforme desenhado na Figura 1, este ponto está acima da curva de indiferença dos residentes locais até o ponto E. Os moradores locais, neste caso, seriam bem servidos por formuladores de políticas locais que dirigem o nível do serviço público produzindo externalidade para 0 , induzindo uma maior assistência do governo de nível superior. Isso é vantajoso para os residentes locais, mesmo se eles sacrificarem o "controle" sobre a prestação de serviços públicos locais, ou seja, mesmo que o nível de serviços públicos cai para um nível que satisfaça os desejos de não residentes, sem qualquer referência aos benefícios locais. Tal situação pode ser chamada de "resgate": as autoridades de nível superior assumiram a responsabilidade pela provisão e financiamento de serviços públicos locais, a fim de elevá-los a níveis que satisfaçam as demandas de eleitores externos. A fim de assegurar que os recursos sejam realmente gastos com os serviços locais que produzem a externalização, o governo de nível superior precisaria impor controles sobre a autonomia local; especificamente, precisaria garantir que os fundos que ele fornece são usados apenas para a prestação dos serviços públicos que produzem os benefícios externos e não convertido em bem de consumo privado ou equivalente.

Esta análise simples sugere razões pelas quais os "resgates" podem às vezes ocorrer e as razões pelas quais eles nem sempre ocorreram. Considere, por exemplo, a indiferença curvas $\mathrm{U}^{c}$ e $\mathrm{U}^{c^{\prime}}$ representando as preferências de não residentes. À medida que são desenhados, os não residentes conferem um valor considerado pequeno ao serviço público local quando é fornecido no nível socialmente eficiente $z^{*}$, como refletido em uma curva de indiferença relativamente plana no ponto $\mathrm{H}$, mas esse valor sobe drasticamente como o nível do serviço público local cai para z. Isso significa que os não residentes estão preparados para pagar muito para garantir um nível "mínimo" de prestação do serviço público. Por exemplo, devido a preocupações com epidemia ou simplesmente por altruísmo, os não residentes podem conceder um valor a disponibilidade de água potável em uma localidade. Em contrapartida, a disponibilidade de um abastecimento local de água e capacidade de tratamento suficientes para sustentar a atividade industrial, os campos de golfe ou as 
lavagens de carros - um nível mais alto de $\mathrm{z}$ - pode ser de menor importância para os não residentes. Nesses casos, o governo de nível superior não pode se abster de forma aceitável em fornecer pelo menos um nível mínimo de serviços locais, porque eles são altamente valorizados por não residentes. É claro que, mesmo nessa situação, o nível de apoio oferecido pelas autoridades de nível superior pode ser bastante limitado - correspondente, na Figura 1, ao caso em que o ponto $\mathrm{H}$ e o correspondente nível de "resgate" do serviço público $\mathrm{z}$, tende muito mais para a esquerda. Com um valor suficientemente baixo de $z$, o ponto $E$ poderia estar abaixo da curva de indiferença local Ul, o que significa que os residentes locais prefeririam fornecer o nível socialmente eficiente de serviços públicos $\mathrm{z}^{*}$ ao invés de induzir uma "fiança" por autoridades de nível superior. Para resumir esta parte da análise: porque os serviços públicos do governo local produzem benefícios externos, como refletido nas preferências de não residentes, o governo de nível superior pode não conseguir se comprometer a não intervir se houver uma "avaria" em a provisão de serviços públicos locais "essenciais". No entanto, mesmo que tal compromisso não seja razoável, pode não ser vantajoso para os residentes locais induzir um resgate porque valorizam a oportunidade de aumentar o nível de serviços públicos locais acima do nível "mínimo" governo, agindo no interesse de não residentes, estaria disposto a fornecer.

Como acabamos de ver, as preferências dos não residentes afim de desempenhar um papel importante para determinar se as ações locais podem desencadear a intervenção de autoridades de alto nível e, em caso afirmativo, o que acontece com os serviços públicos locais (ou seja, determinar z) no caso de uma intervenção externa. Se essa intervenção é desejável do ponto de vista dos residentes locais, por outro lado, depende criticamente das preferências locais. Na Figura 1, a questão crítica, como vimos, é se o ponto E está acima ou abaixo da curva de indiferença Ul, e é óbvio que isso não pode ser determinado a priori. Se a curva de indiferença Ul apresentar uma alterabilidade muito limitada entre x e z num caso extremo, se estes produtos são perfeitamente complementares, de modo que a curva de indiferença é em forma de L com um canto em $\mathrm{E}$ - então o ponto E estará necessariamente situado abaixo da curva de indiferença através de E. Isto corresponde a um serviço público sobre o qual os residentes locais buscarão esforços no sentido de manter o controle local. Por exemplo, os residentes de um estado ou localidade podem ter preferências muito fortes para controlar o currículo ou a escolha de livros didáticos nas escolas dos seus filhos e não estariam 
dispostos a renunciar a isso, mesmo que as autoridades de nível superior pagassem por muito ou todo o resto dos custos escolares locais. Se, por outro lado, as preferências locais entre o serviço público e outros bens exibem alta substituibilidade - ou seja, se a curva de indiferença Ul é muito plana - então o ponto E, o resultado para residências locais no caso de um resgate, provavelmente será preferido para o resultado socialmente eficiente em E. Isso corresponderia a um caso em que o "controle" sobre o nível do serviço público não é muito importante para os residentes locais, no sentido que podem facilmente substituir outros bens em troca do serviço público. Quando uma redução no nível do serviço público para um nível como $\mathrm{z}$ não é muito prejudicial aos residentes locais, eles têm um incentivo para reduzir as despesas locais na atividade, economizando recursos locais para usos de maior prioridade e adiando preferências de não-residentes, representadas pelas ações de um governo de nível superior.

É fácil experimentar as configurações de preferência na Figura 1 para ver em que condições os governos locais forneceriam um serviço público local para atrair o apoio de fora - o caso de "resgate" e em que condições as localidades prefeririam aderir a (ou, talvez, melhor, participar voluntariamente) qualquer programa de transferências que os governos de nível superior possam oferecer a eles. Como um caso especial importante, uma atividade local pode gerar nenhum benefício adicional; neste caso, a curva de indiferença $U^{c}$ torna-se uma linha horizontal e a taxa de correspondência ótima é zero. Nesse caso, não há externalidades para internalizar, não há necessidade de uma concessão de correspondência e nenhuma possibilidade de um governo de nível superior intervir para manter a provisão do serviço público se a localidade não o fizer; a restrição do orçamento local neste caso é definitivamente "difícil", não há possibilidade de resgate e o resultado de equilíbrio da tomada de decisão descentralizada é eficiente. Como outro caso extremo, é possível que algum serviço local não ofereça nenhum benefício aos residentes locais, mas que beneficia os não residentes. Neste caso, a curva de indiferença local Ul é uma linha horizontal, e os residentes locais nunca escolherão fornecer um nível positivo do serviço público. Nesse caso, o montante socialmente eficiente do serviço público seria $\mathrm{z}$, o valor que os não residentes prefeririam suportar quanto ao custo total do serviço. A prestação do serviço público por um governo de nível superior é certa nesse caso e esse resultado também será socialmente eficiente. Nos casos intermediários, onde os residentes e os não residentes se beneficiam do serviço público, são possíveis resultados eficientes, como, por exemplo, sob um esquema de bolsas de correspondência ideal, 
mas nem sempre são sustentáveis. Se a configuração das preferências locais e não residentes é tal que os resgates não ocorrem e a restrição orçamentária local é "difícil", então um resultado socialmente eficiente pode ser alcançado através de uma concessão de correspondência ideal. Se as preferências de residentes e não residentes são tais que os residentes locais estão melhor com um resgate, eles irão explorar a restrição do orçamento suave para sua vantagem. O resultado final neste caso não é socialmente eficiente como um todo, uma vez que as políticas locais são definidas de acordo com as preferências dos não residentes.

Este modelo simples e deliberadamente estilizado pode ser ampliado imediatamente de várias maneiras. Em primeiro lugar, para ilustrar a análise de forma esquemática, considerou que existe apenas um bem público local, o que pode deixar a impressão de que os resgates provavelmente serão observados quando os níveis de gastos públicos locais forem baixos. No entanto, existem na prática muitos tipos de serviços públicos locais e despesas públicas locais, que não produzem benefícios externos significativos. A análise anterior sugere que as autoridades de nível superior podem intervir com um resgate, mesmo que as despesas públicas locais sejam muito elevadas, se essas despesas fossem dedicadas a serviços públicos locais "não essenciais" - isto é, serviços públicos que não produzam externalidades significativas . No diagrama simples da Figura 1, o "consumo privado" $x$ deve ser interpretado para incluir todas as utilizações de recursos locais que não sejam aqueles que produzam externalidades significativas para não residentes, incluindo algumas categorias de despesas públicas locais.

Ao assumir que todas as famílias dentro de uma localidade têm preferências e rendimentos idênticos, assim como todos os não residentes, a análise se concentra na interação dos interesses dos que estão dentro e fora da localidade. $O$ relaxamento desses pressupostos simplificadores proporcionaria um papel importante para a política local e não local dentro do modelo, talvez levando a novos conhecimentos importantes. As tensões fundamentais entre os interesses de residentes e não residentes, destacadas de forma mais transparente no modelo simples acima, provavelmente não desaparecerão em tal modelo, mas seus efeitos serão mitigados por outros fatores.

Como uma observação estreitamente relacionada, deve-se notar que a corrupção e a má governança às vezes podem prejudicar as instituições locais e desencadear intervenções de governos de nível superior. Suponhamos, por exemplo, que funcionários corruptos desviem recursos fiscais locais para uso privado, talvez canalizando altos níveis de gastos 
públicos locais em pagamentos a fornecedores políticos. Tais desvios diminuirão o nível de provisão de serviços públicos locais "essenciais" (z na Figura 1). Se qualquer uso dado de recursos fiscais locais é considerado corrupto depende das particularidades do caso, mas, para fins de interpretação do modelo, a questão crucial é se a localidade está usando seus recursos para garantir níveis "suficientemente altos" de prestação de serviços externos de produção pública. Neste contexto, a tensão entre as demandas externas e os interesses das autoridades locais e a ansiedade em que se envolvem às vezes é capturada pela resposta do prefeito Barry de Washington, DC à intervenção do Congresso nos assuntos do distrito: "Mayor Marion Barry ... opposed the efforts of a member of Congress to provide $\$ 42$ million to the D.C. police department. He said it would be unfair to single out the police department for additional funds when all city agencies are in financial straits." (Washington Post, 30 de março de 1996, p. A8, col. 6).

Finalmente, o modelo simples desenvolvido na Figura 1 abstrai de considerações dinâmicas, colapsando muitos eventos, que podem ocorrer em um período bastante prolongado, em um único evento. Por exemplo, a crise fiscal dos governos estaduais no Brasil se desenvolveu durante um período considerável, durante o qual o endividamento do Estado acumulou, a solvência dos bancos estaduais foi gradualmente colocada em risco e essas dívidas foram então absorvidas pelas autoridades de nível superior. O modelo acima se concentra nas consequências da solução "óbvia" para a insolvência dos governos estaduais: eles poderiam simplesmente ser autorizados a declarar falência e deixar resolver seus problemas fiscais por conta própria, uma solução que exigiria uma reestruturação do público local despesas e impostos, de modo a alcançar o saldo fiscal, provavelmente ao custo de interrupções significativas da prestação de serviços públicos (incluindo desordem pública e interrupção econômica decorrente de demissões ameaçadas e cortes salariais para funcionários do setor público). Esse ajuste poderia ser distribuído ao longo do tempo por meio da recusa em cumprir as obrigações de dívida pendentes, o que provavelmente resultaria em acesso futuro limitado ou mais caro aos mercados de crédito e, portanto, para opções fiscais menos favoráveis em períodos futuros. Essas consequências, que poderiam ser um pouco duradouras, seriam dispendiosas para o resto da sociedade - o efeito de destruição da provisão de serviços públicos locais - e, assim, um governo de nível superior não pode permitir que elas se desenvolvam. $\mathrm{O}$ modelo ilustrado na Figura 1 efetivamente reduz esse processo complexo para uma escolha simples por parte dos governos de nível mais baixo e superior. $O$ primeiro deve decidir se deve seguir um curso de ação levando à descontinuidade de serviços públicos "essenciais" e o último 
deve decidir se tal colapso é suficientemente dispendioso para o resto da sociedade para justificar uma infusão suficiente de recursos fiscais para evitar isso . O modelo, assim, destaca o papel crítico da natureza de serviços públicos locais - sua importância para os residentes locais e para os não residentes - ao determinar se as restrições orçamentárias locais são "duras" ou "suaves".

Um modelo tão simples pode, na melhor das hipóteses, esclarecer as determinantes estruturais do comportamento fiscal e das relações intergovernamentais. Na prática, os resgates de governos de nível inferior, como falências comerciais, são desencadeados por eventos imediatos - uma desaceleração do ciclo econômico, por exemplo. Um modelo que tenta explicar o tempo preciso de resgates, para não mencionar outros fenômenos intrinsecamente dinâmicos, como a construção de reputação por governos de nível superior ou inferior, deve conter mais estrutura intertemporal do que a mostrada na Figura 1.

\section{A ATRibuição FUnCiONAL E A ESTRUTURA INTERGOVERNAMENTAL DO EMPRÉSTIMO PÚBLICO}

A presente seção explora algumas das possíveis implicações sugeridas pela análise anterior para entender os arranjos institucionais em uma federação e para empréstimos por governos subnacionais. Concentra-se em duas questões: primeiro, na atribuição de responsabilidade pela prestação de serviços públicos entre os níveis de governo e, em segundo lugar, na divisão da autoridade de empréstimo entre os níveis de governo. Ambas levantam questões de estrutura institucional. De uma perspectiva positiva, podemos perguntar como os arranjos existentes são como são e quais os seus efeitos. De uma perspectiva normativa, podemos procurar compreender os benefícios e os custos dos arranjos alternativos para melhorar as estruturas institucionais. Tal como será aparente, existem importantes questões de pesquisa aberta em cada uma dessas áreas. Deveria ser possível ampliar a pesquisa anterior em finanças públicas, organização industrial e economia monetária para fazer avanços úteis sobre eles.

\section{A atribuição de funções de despesas}

A análise na seção anterior sugere que quando os não residentes estão preocupados com algumas políticas locais (há externalidades), quando os residentes não colocam um alto valor no controle local sobre a política 
(eles não são muito prejudicados quando a política é definida de acordo com preferências externas e não locais) e quando os não residentes estão preparados para pagar para manter quantidades significativas de um serviço público na ausência de provisão local, as ações locais são susceptíveis de desencadear intervenções por um governo de nível superior quando os recursos das autoridades de nível superior são usadas para alcançar resultados locais que atendam os interesses dos não residentes.

Empiricamente, parece que essas intervenções tomam uma das várias formas, correspondendo a diferentes arranjos institucionais. Uma possibilidade é que um governo de nível superior possa intervir para tomar controle temporário das políticas fiscais locais. Normalmente, órgãos administrativos especiais ("comissões de controle financeiro" ou similares) são estabelecidos em tais situações (GAO, 1995), a fim de evitar o controle do governo local pelos legitimados. Esses órgãos podem realizar auditorias, renovar contratos, estabelecer prioridades orçamentárias, instituir novos sistemas de gestão e exercer outros poderes extraordinários para restabelecer a ordem e a solvência das finanças locais, para assegurar que os fundos externos sejam direcionados para a provisão de serviços públicos "essenciais" e para cumprir as obrigações da dívida - possivelmente à custa de cortes no pessoal de alguns programas locais ou na compensação ("excessiva") de funcionários locais do setor público, ou para impedir o desvio de recursos fiscais locais para uso privado através de desfalque, roubo, contratação pública ou outra finalidade. Tal resultado não é diferente da reorganização de uma empresa em falência, onde um tribunal assume poderes extraordinários temporariamente para resolver os problemas financeiros de uma empresa, seja seguido pela liquidação da empresa ou sua reorganização. Todavia, a liquidação não é uma opção viável para alguns governos locais ${ }^{12}$. No entanto, surge a questão de saber se um governo local "reorganizado" pode ser fiscalmente e financeiramente viável. Em alguns casos, onde as condições locais são aparentemente remediáveis (corrupção, sistemas de gestão incorretos, contratos de empregados públicos locais indesejáveis) parecem estar na raiz dos problemas fiscais da localidade, as reformas administrativas e fiscais podem bastar para

12 É certamente possível dissolver algumas unidades governamentais locais, como transporte, hospital, água ou autoridades de poder. No caso dos governos municipais ou de condados, no entanto, a questão não é a de ter uma autoridade local, mas sim a forma que ela irá tomar. 
restabelecer a localidade como um funcionamento entidade independente.

Entretanto, em outros casos, podem ser necessárias mais mudanças fundamentais. Por exemplo, suponha (como foi frequentemente sugerido no contexto dos EUA) que as cidades centrais estão sujeitas a um estresse fiscal persistente porque devem fornecer serviços públicos para passageiros não residentes e compradores que não estão sujeitos a tributação pelas cidades nas quais eles gastam substancialmente - em tempos difíceis. Uma reforma administrativa única das finanças municipais não aborda tais problemas estruturais. Nesses casos, exemplificado pela relação de externalidade mostrada na Figura 1, pode ser necessária uma mudança institucional mais básica. Uma possibilidade é que uma combinação de transferências e regulamentos fiscais (subsídios, por exemplo) pode fornecer um quadro viável dentro do qual os interesses dos não residentes podem ser acomodados na definição de políticas locais. Como os incentivos de correspondência mostrados na Figura 1, tais políticas não precisam interferir com a autonomia de gastos e receitas dos governos locais. As transferências fiscais deste tipo, como as transferências fiscais maciças e persistentes dos governos federais para estaduais e locais documentados na segunda seção deste artigo, não constituem "resgates" e não sinalizam crises fiscais ou financeiras locais. Eles se tornam parte da estrutura institucional estabelecida das relações fiscais intergovernamentais e podem ser vistos como a incorporação institucional de uma solução Coasiana a um fenômeno de efeitos (COASE, 1960), ou seja, um contrato entre locais residentes e não residentes, em que estes fornecem incentivos para que aqueles escolham políticas que levem em conta os efeitos das consequências.

Tais contratos não assumiriam necessariamente a forma de parcerias simples, como as apresentadas na Figura 1. De fato, a alocação da provisão de serviço público local ilustrada poderia ser evitada por transferências fiscais suficientemente complexas (não-lineares) ${ }^{13}$ entre as autoridades de governos altos e baixos. No entanto, na prática, os requisitos de informação de tais acordos podem impor custos de informação desordenadas. Por exemplo, os custos associados a acordos

${ }^{13}$ Uma combinação de incentivos de correspondência e de montante fixo pode ser vista em contratos de duas partes. Na Figura 1, tais contratos afetariam tanto as interceptações quanto as rubricas orçamentais para domicílios de residentes e não residentes. Programas de concessão mais completos poderiam produzir restrições por partes ou possivelmente altamente não-lineares. 
de transferência de impostos altamente individualizados entre os governos estaduais e as dezenas de milhares de governos locais encontrados nos EUA, incluindo não apenas os custos de coleta de informações, mas também a transparência e a falta de manipulação ou abuso por parte das autoridades locais ou estaduais, poderia facilmente tornar-se proibitivo. Por estas razões, pode-se esperar por acordos administrativos e fiscais especiais e mais complexos das principais jurisdições (por exemplo, para "cidades de primeira classe", uma designação comum baseada na população usada nos estatutos e regulamentos do governo estadual de propriedade dos governos locais, uma classe que geralmente contém apenas uma ou algumas cidades principais dentro de um estado), enquanto relativamente simples os mecanismos regulatórios e de financiamento são usados para lidar com localidades menores e mais numerosas ${ }^{14}$. No entanto, como sugerido na figura 1, arranjos comparativamente simples para transferências intergovernamentais que são viáveis na prática podem não ser sustentáveis, na medida em que não produzem incentivos para a formulação de políticas locais que antecipam as intervenções das autoridades de nível superior. Nesses casos, a análise teórica prevê um controle sustentado e o financiamento da prestação de serviços públicos por um governo de nível superior.

Este resultado equivale a um acordo institucional que Oates (1972) caracterizaria como provisão "economicamente centralizada" do serviço público, quer a provisão e o financiamento do serviço sejam executados diretamente pela autoridade do nível superior do governo ("centralização política") ou se a autoridade do nível superior do governo simplesmente remove a autonomia fiscal efetiva do governo local ("centralização econômica com descentralização política") ${ }^{15}$. Como sugerido pelo "teorema da descentralização" de Oates (1972), tal centralização da

\footnotetext{
${ }^{14}$ A análise de Ades e Glaeser (1995) sugere que as grandes cidades podem efetivamente capturar aluguéis do resto da sociedade em virtude de seu status especial. $\mathrm{O}$ estabelecimento de tratamento fiscal especial para essas cidades é um mecanismo através do qual isso pode ocorrer.

${ }^{15}$ Embora a centralização econômica e política seja logicamente independente, os custos de transação que surgem quando os governos de nível superior tentam controlar e financiar os serviços públicos de governos de nível inferior sugerem que ambos coincidem na prática. Pela teoria de Coase (1937), mudar uma atividade do setor público inteiramente nas mãos de um governo de nível superior pode ser a estrutura institucional de menor custo para implementar uma política centralizada.
} 
tomada de decisão ocorre em um custo. Na Figura 1, este é o custo associado à provisão do nível $\mathrm{z}$ do bem público, um resultado socialmente ineficiente que reflete os interesses dos não residentes, mas que não responde às preferências locais.

O problema da "atribuição de despesas" em um sistema federal tem sido abordado sob uma perspectiva normativa. Alguns autores discutiram o "mapeamento" de fronteiras jurisdicionais para as áreas de serviço associadas a diferentes serviços públicos, sugerindo que as localidades deveriam ser atribuídas a função de desempenhar as tarefas para as quais os benefícios se acumulam exclusivamente ou pelo menos predominantemente para os residentes locais e que as atividades com benefícios diversos em áreas geográficas mais amplas devem ser atribuídas a governos de nível superior. Uma vez que esses mapeamentos são inevitavelmente imperfeitos, é provável que ocorram alguns efeitos indiretos para quase todos os serviços que possam ser deixados nas mãos de governos de nível inferior. Para evitar esse problema, a provisão de serviço público sempre pode ser redistribuída para os governos de nível superior, mas não haverá papel para os governos locais executarem. E, como afirma o "teorema de descentralização" de Oates (1972), a reafetação ascendente implica falta de controle local na configuração de níveis de serviço público de acordo com as preferências locais. As transferências intergovernamentais ideais fornecem uma possível solução normativa para o problema da "organização do setor público", ou seja, para encontrar uma atribuição de responsabilidades de despesa entre os governos que alcança resultados socialmente eficientes.

Deve ser evidente que existe um forte paralelismo entre esses princípios normativos e a discussão anterior das limitações orçamentárias suaves. Quando os excessos são modestos e onde o controle local de serviços é particularmente valioso, as funções atribuídas aos governos locais provavelmente serão realizadas de forma relativamente eficiente. Os programas de subsídios corretivos podem fornecer um mecanismo através do qual os interesses do resto da sociedade podem ser representados de forma significativa para os residentes locais. No entanto, assim como as imperfeições na contratação podem desempenhar um papel importante na explicação da organização observada nas empresas e nas instituições que são financiadas e administradas, de modo que as imperfeições nas relações fiscais intergovernamentais podem desempenhar um papel importante ao explicar por que as tarefas de desembolso das funções de gastos menos do que perfeitas entre os 
governos podem surgir em um sistema federal. ${ }^{16}$ As crises financeiras e fiscais podem refletir as atribuições de "desequilíbrio" das responsabilidades entre os governos, exigindo uma reestruturação institucional para chegar a acordos sustentáveis, assim como as falências de empresas privadas geralmente desencadeiam a sua reorganização.

\section{A Estrutura da Dívida Pública em uma Federação}

As preocupações com o endividamento do setor público estão sempre presentes. A história está cheia de exemplos de governos que realizaram empréstimos de forma excessiva, levando a crises financeiras, hiperinflações e transtornos civis. Esses exemplos testemunham os custos potenciais associados à administração do governo. Os benefícios potenciais do empréstimo do governo também são substanciais. Em particular, o empréstimo do governo permite a redução de impostos ao longo do tempo, como enfatizou Barro (1979). A otimização da estrutura tributária intertemporal não só reduz as perdas de peso morto da tributação, mas também reduz o custo marginal dos fundos públicos. Se os governos desperdiçam recursos, esta é uma desvantagem associada a estruturas fiscais mais eficientes (BRENNAN; BUCHANAN, 1980). Se a atividade redistributiva do governo for limitada por distorções fiscais (MELTZER; RICHARD, 1981), uma tributação mais eficiente permite uma maior redistribuição, para o bem ou para o mal. Por último, mas não menos importante, se os governos gastam recursos em projetos que beneficiam os governados, uma tributação mais eficiente permite que as despesas públicas de melhoria do bem-estar aconteçam. Todas essas considerações podem entrar em jogo ao analisar as políticas de dívida dos governos subnacionais. No entanto, não é imediatamente claro como se tratar as políticas de dívida dos governos subnacionais em relação às de autoridades de nível superior, embora esta seja claramente uma questão de importância vital para lidar com questões de restrições orçamentárias suaves e resgates.

\footnotetext{
${ }^{16}$ Como sugerem essas observações, pode haver muitos paralelos importantes entre os problemas de "organização industrial" e os problemas de "organização do setor público" que surgem em um sistema federal, indicando muitas direções úteis para análises futuras. Por exemplo, a análise na Figura 1 tem alguma semelhança com a Proposição 2 em Hart (1995). Veja Hart (1995) e Tirole (1999) para discussões muito estimulantes sobre os fundamentos da teoria dos contratos e muitas referências à literatura relacionada.
} 
Retomando a discussão na segunda seção do presente trabalho onde observou-se que o governo federal transfere grandes quantidades de recursos, de forma explícita e implícita, aos governos subnacionais. Como política fiscal alternativa, suponha que o governo federal tenha cessado todas essas transferências, reduzindo assim esse componente de suas despesas, mantendo outras despesas e seus impostos nos níveis atuais. $\mathrm{O}$ déficit federal cairá em um montante igual à magnitude das transferências fiscais para os governos subnacionais. Suponha que os governos subnacionais, diante dessa redução nas transferências federais, fossem aumentar seus empréstimos em igual montante, mantendo seus próprios gastos e impostos fixos. O efeito líquido desta combinação de políticas seria transferir o empréstimo do governo de nível federal para o subnacional, deixando inalterados não apenas o montante total de empréstimos do governo, mas também os níveis de impostos e serviços públicos em cada nível de governo. Em outras palavras, uma mudança nas transferências intergovernamentais pode ser perfeitamente compensada por uma mudança na estrutura da dívida pública, ou seja, uma mudança nos montantes de empréstimos empreendidos em diferentes níveis de governo. Do mesmo modo, o empréstimo do governo subnacional poderia ser completamente eliminado, sendo compensado em sua totalidade por um aumento nas transferências federais e por um aumento nos empréstimos do governo federal. As transferências intergovernamentais, em outras palavras, afetam a estrutura da dívida pública e, inversamente, pelo menos nesse simples sentido contábil. Em termos diferentes, a estrutura da dívida e a estrutura das relações fiscais intergovernamentais são, em alguns aspectos, dois lados da mesma moeda.

Muitas investigações teóricas e empíricas chamaram a atenção para a importância da economia política e das estruturas institucionais na determinação da medida em que os governos dependem da dívida para financiar suas operações. Questões como a redistribuição intergeracional, a reputação e a credibilidade dos formuladores de políticas, a organização institucional da decisão política (por exemplo, os papéis das autoridades executivas e legislativas), a independência do banco central, a mobilidade do capital internacional e as políticas cambiais e o papel da coordenação das políticas internacionais foram extensivamente examinadas. (Veja Drazen (2000) e Persson e Tabellini (2000) para discussões aprofundadas sobre esses temas e para muitas referências à literatura. Obstfeld e Rogoff (1996) se concentram nas dimensões internacionais da política fiscal e monetária.) Nesta vasta literatura, no entanto, a estrutura 
intergovernamental das dívidas do setor público parece ter recebido relativamente pouca atenção. No entanto, como é evidente a partir dos dados apresentados na segunda seção deste artigo, os governos subnacionais representam uma parcela muito importante da dívida do setor público nos EUA, mesmo quando eles são receptores de transferências muito substanciais do governo federal. As observações paralelas aplicam-se igualmente no contexto das transferências fiscais intergovernamentais estaduais / locais e dos empréstimos do governo estadual / local. E a literatura sobre resgates e empréstimos do governo subnacional se concentra diretamente na conexão entre a estrutura da dívida e as transferências intergovernamentais. Existem inúmeras questões abertas que merecem uma análise mais aprofundada neste contexto: o que determina quanto empréstimo ou se deve o empréstimo ser realizado em cada nível de governo? Se o governo nacional é capaz de emprestar, realmente importa se os governos subnacionais também podem pedir emprestado? Seria possível simplesmente "delegar" as responsabilidades do empréstimo ao governo nacional e gerenciar qualquer lacuna entre as despesas do estado e a tributação através de transferências intergovernamentais, ou a descentralização fiscal efetiva exige alguma "autonomia da dívida" para os níveis inferiores de governos ao longo com autonomia de receitas e despesas?

Se as transferências intergovernamentais funcionam sem custos e se os custos reais dos empréstimos por parte dos governos de nível superior e inferior são iguais, a estrutura intergovernamental dos empréstimos governamentais é uma questão de indiferença. No espírito do teorema de Modigliani-Miller, poderiam ser alcançados resultados equivalentes se a aprovação de governos de nível superior ou inferior fosse arbitrariamente limitada. De modo geral, entretanto, um nível de governo ou outro pode ter uma vantagem comparativa em empréstimos. Por exemplo, os custos de transações associadas ao empréstimo podem tornar vantajoso para os governos subnacionais não emprestarem empréstimos e para que seus "requisitos de empréstimos" sejam atendidos inteiramente por um governo de nível superior que, como consequência, engloba empréstimos de muitos níveis inferiores de governo em uma única operação de dívida, desembolsando o produto do seu empréstimo para este último sob a forma de transferências intergovernamentais. Esta é uma maneira de ver algumas das grandes transferências explícitas e implícitas feitas pelo governo federal nos EUA para os estados e localidades: o governo federal endividado atua em parte como um intermediário financeiro em favor deste último.

Não obstante, por óbvio os governos subnacionais ainda dependem 
fortemente do acesso direto aos mercados de capitais. Isso pode refletir as imperfeições de mecanismos viáveis de transferências intergovernamentais. Como as transferências intergovernamentais, o empréstimo permite que as localidades superem as restrições de liquidez e, portanto, realizem gastos de investimento, alinhem as flutuações da receita de curto prazo ou gerenciem o fluxo de caixa com eficiência. $\mathrm{O}$ acesso aos mercados de capitais, como o acesso a qualquer mercado, é potencialmente valioso para os participantes do mercado. $\mathrm{O}$ valor desse acesso aos governos estaduais e locais decorre, em parte, do fato de que as transferências intergovernamentais não atendem tão bem a essas necessidades. Para o conhecimento desse autor, não há análises das finanças públicas subnacionais que tentaram determinar as perdas de bem-estar que resultariam de uma proibição de empréstimos por parte desses governos, mas, tendo em vista grandeza desse empréstimo, podese presumir que serve um propósito econômico útil e que sua proibição impõe um custo social substancial. Este custo não é meramente o custo associado à falta de alavanca fiscal intertemporal ou com acesso inadequado a fundos para investimento; é também o custo associado a transferências intergovernamentais imperfeitas que podem, até certo ponto, servir de alternativa aos empréstimos subnacionais do governo. $\mathrm{O}$ que, então, são os custos associados a essas transferências? Presumivelmente, eles se relacionam com os custos de reunir informações sobre os requisitos de crédito dos governos subnacionais. As instituições financeiras privadas podem ter incentivos para serem mais eficientes do que os governos centrais na determinação da solvabilidade dos bancos subnacionais. Estes últimos têm incentivos para serem solventes se o custo para os residentes locais perderem o controle sobre os serviços públicos locais é alto, ou seja, se as funções de despesa forem atribuídas entre os governos de tal forma que suas restrições orçamentárias sejam "difíceis".

\section{ORIENTAÇÃO PARA PESQUISA ADICIONAL}

As observações anteriores abordaram uma grande variedade de questões, incluindo relações fiscais intergovernamentais, política de dívidas e atribuição de funções em um sistema federal. E já levantaram muito mais questões do que responderam. Esta seção oferece algumas sugestões de tentativas adicionais para futuras pesquisas, incluindo pesquisas empíricas, reunindo alguns dos temas de seções anteriores. 


\section{O que são "Resgates" e "Restrições de orçamento flexível"?}

Conforme mencionado anteriormente, apesar dos inúmeros estudos de caso de resgates e restrições de orçamento suaves em outros países, nem todas as transferências intergovernamentais são "resgates" e, no entanto, a definição operacional de um resgate é bastante sutil. Do ponto de vista empírico, como distinguir os resgates de outros tipos de transferências intergovernamentais? ${ }^{17}$

Um caminho potencialmente frutífero de investigação é explorar a dinâmica do ajuste fiscal. Os governos subnacionais experimentam desequilíbrios ou crises fiscais decorrentes de uma ampla gama de causas. Perdas por desastres naturais, como terremotos, inundações ou furacões, afetam a demanda por gastos públicos - para reconstruir infraestrutura danificada, por exemplo. Através da interrupção da atividade econômica e da destruição de recursos valiosos, esses eventos também afetam o fluxo de receitas de impostos e outras fontes. De forma menos dramática, as flutuações do ciclo econômico, as mudanças demográficas e muitos outros eventos influenciam tanto os gastos quanto os lados da receita das finanças públicas subnacionais. Como esses governos se ajustam a tais eventos?

Quando um governo experimenta um colapso fiscal, é preciso tomar medidas para aumentar as receitas adicionadas, cortar despesas ou aumentar empréstimos? A dinâmica do ajuste fiscal a nível nacional tem sido investigada utilizando métodos de séries temporais por autores como Bohn (1991). No caso dos governos subnacionais, a assistência de governos de nível superior proporciona uma margem adicional de ajuste potencial para choques fiscais. Os governos de nível superior participam de financiamentos adicionais para governos subnacionais? A análise empírica pode ajudar a descobrir o ajuste que os governos subnacionais seguem e, portanto, talvez esclarecer sobre se e em que medida enfrentam restrições orçamentárias "suaves". Exemplos de pesquisas nestas linhas incluem Buettner e Wildasin (2003), que acham, por exemplo, que os grandes municípios dos EUA seguem caminhos de ajuste bastante diferentes do que os menores, com os primeiros confiando mais na assistência de governos de nível superior do que o último. A mecânica precisa através da qual esses ajustes ocorrem, como eles podem ser influenciados por diferentes fatores institucionais (regulamentos sobre

\footnotetext{
17 Pettersson-Lidbom e Dahlberg (2003) abordaram esta questão no contexto sueco, concluindo que os governos locais receberam 1.697 resgates entre 1974 e 1992.
} 
empréstimos, acordos fiscais intergovernamentais, regras de governança, mobilidade de moradores ou capital (ver, por exemplo, Bruce (1995)) e , portanto, em última análise, como as instituições incorporam incentivos e influenciam o comportamento são questões que exigem mais investigação empírica.

\section{Organização e Finanças}

Embora a discussão anterior tenha se concentrado em questões de finanças públicas e políticas públicas, existem questões muito análogas que surgem no contexto do setor privado. As empresas, por exemplo, emprestam dinheiro e às vezes falham. No processo de entrega de bens e serviços finais, muitas vezes muitas empresas são vinculadas através de uma estrutura de transações (empresas a montante/sucessora) e, de alguma forma, tarefas específicas são atribuídas a empresas específicas. Algumas vezes, as empresas se fundem ou se separam. Qual é a maneira mais eficiente de atribuir tarefas às empresas? Todas as tarefas devem ser atribuídas a uma grande empresa? Essas questões foram objeto de estudo intensivo na literatura de finanças e organização industrial. O estudo dos sistemas de governo federais e os arranjos financeiros através dos quais são implementados - organização do setor público e finanças públicas podem emprestar com rentabilidade do estudo de organização industrial e financiamento privado.

Grande parte desta literatura, que a traça para o trabalho fundamental sobre os direitos de propriedade e os custos de transações (por exemplo, Coase $(1937,1960))$, gira em torno da forma como diferentes estruturas organizacionais e arranjos financeiros afetam os incentivos. A relação entre "propriedade" e "controle" é fundamental para a teoria da empresa (ver Hart (1995)). Não é completamente óbvio como se pode definir "propriedade" e "controle" para governos subnacionais. Existem "reivindicadores residuais" que sofrem as consequências do sofrimento financeiro local ou que colhem os benefícios de resultados financeiros locais favoráveis? Estes podem ser alguns ou todos os seguintes: (a) residentes locais, que sofrem cortes em serviços públicos locais ou que carregam o ônus de impostos adicionais em caso de desequilíbrios fiscais, (b) os proprietários de terra ou outros imóveis de renda, ativos cujos preços são determinados em parte pelas condições fiscais locais, (c) funcionários do setor público local, que sofrem despedimentos ou reduções na compensação quando as finanças são estressadas, ou (d) contribuintes fora da localidade, que indiretamente absorvem perdas 
financeiras locais quando um governo de nível superior intervém para fornecer assistência financeira sob a forma de resgates. As considerações teóricas apontam para (b) em vez de (a) ou (c), pelo menos a "longo prazo", assim como os estudos empíricos de capitalização de políticas fiscais locais em valores de propriedade. Os moradores locais não estão perfeitamente móveis num "curto prazo" e os funcionários locais do setor público não podem encontrar um emprego igualmente atrativo em outros lugares em caso de demissões ou reduções de compensação. Na medida em que os residentes locais ou os trabalhadores do setor público são menos do que totalmente móveis (ver Wildasin (2003) para análises relacionadas), eles gozam de semi-rendas que podem ser consumida ou melhoradas dependendo das vicissitudes do público local finanças e, em termos de valor presente, essas mudanças de "curto prazo" (semi) rendas podem determinar quais agentes têm o maior impacto das mudanças nas políticas fiscais locais.

As instituições existentes, de alguma forma, transmitem colapsos fiscais aos agentes econômicos locais, através do ajuste das políticas locais de receita, despesas, empréstimos e contratação, bem como através de transferências fiscais intergovernamentais. $O$ funcionamento deste mecanismo de transmissão certamente não é claro a priori. Uma melhor compreensão é questão chave para a pesquisa empírica, uma vez que os incentivos de diferentes agentes para influenciar o processo político local e, assim, as políticas observadas, são determinados pelo grau em que as políticas locais afetam seu bem-estar. Como, empiricamente, as instituições observadas distribuem a "propriedade" das políticas fiscais locais? Eles efetivamente alinham o "controle" com a "propriedade" e, assim, criam incentivos para o financiamento ordenado do governo?

\section{CONCLUSÃo}

A evolução das instituições do federalismo americano começa com a fundação da república e o design constitucional original. A experimentação de estados e governos locais e suas reações a mudanças econômicas, demográficas e outras condições levaram a mudanças graduais nos sistemas de gastos e receita dos governos em todos os níveis. No espírito de Hayek (1945) e Boulding e Winter (1982), é natural ver essa evolução não (ou não exclusivamente) como resultado de esforços de indivíduos informados que buscam moldar políticas e instituições, mas sim como o resultado de uma interação complexa de decisores descentralizados - os tribunais, os mercados financeiros e outros decisores políticos do governo - que não podem possuir pleno 
conhecimento das consequências de suas decisões. O sistema que evoluiu desta forma, pelo menos, passou por um teste básico de sobrevivência; mais do que isso, como observado desde o início, ajudou a fornecer o quadro dentro do qual os EUA experimentaram um período prolongado de crescimento econômico. $\mathrm{O}$ mesmo pode ser dito de federações maduras em outras economias avançadas.

Como as instituições de federalismo em federações maduras funcionam de forma relativamente efetiva, são relativamente estáveis e se desenvolveram em longos períodos históricos, pode ser difícil discernir seus trabalhos. Ao tentar lançar luz sobre a sustentabilidade de diferentes estruturas institucionais, a discussão anterior centrou-se em vínculos fundamentais entre as jurisdições de nível inferior e as sociedades em que estão localizadas, caracterizadas aqui como benefícios indiretos associados às políticas locais. A descentralização fiscal implica autonomia fiscal local em pelo menos algumas dimensões e, nos Estados Unidos, os governos estaduais e locais gozam e utilizam poder substancial em todas as dimensões da formulação de políticas fiscais: despesas públicas, impostos e empréstimos. Mas as políticas locais afetam a sociedade em geral, dando origem a um sistema extensivo (e sempre em mudança) de transferências e regulamentos fiscais intergovernamentais. Nas federações maduras, as responsabilidades foram distribuídas de algum modo entre os níveis de governo, de tal forma que os governos de nível inferior são livres para exercer um alto grau de autonomia fiscal sem atuar de forma fundamentalmente perturbadora de todo o sistema fiscal e financeiro. A experiência de países que estão recentemente embarcados no caminho do aumento da descentralização fiscal mostra que as estruturas fiscais e financeiras viáveis em uma federação não são, de modo algum, uma conclusão inevitável e uma melhor compreensão dos papéis dos arranjos institucionais nos sistemas federais seria de enorme valor para os formuladores de políticas que tentam encontrar o caminho para uma efetiva estrutura das instituições públicas.

A literatura do federalismo, preocupada com a organização do setor público, pode conseguir emprestar e adaptar abordagens analíticas desenvolvidas na literatura de organização e finanças industriais. Do ponto de vista macroeconômico, atenção notável foi dedicada ao desenvolvimento de um quadro integrado para a análise da política de dívida pública e das relações fiscais intergovernamentais. Conforme observado anteriormente, o desempenho financeiro dos governos subnacionais e a estrutura das relações fiscais intergovernamentais não 
são, por si só, um assunto pequeno para o desempenho financeiro e fiscal global de economias como a dos EUA. Em suma, a análise das instituições de federalismo aponta para questões profundas e fascinantes, de natureza teórica e empírica, que se encontram na interseção de vários ramos principais da análise econômica: finanças públicas, organização industrial, economia financeira e economia macro e monetária.

\section{AgRADECIMENTOS}

Agradeço a Therese McGuire por comentários úteis sobre um rascunho anterior deste artigo, mas sou responsável por erros ou omissões. Em vista da natureza abrangente desta discussão, uma omissão inevitável é uma falha na inclusão de referências a muitos estudos importantes relacionados em ramos distintos da literatura. Como um remédio parcial embora necessariamente inadequado para esta lacuna, particularmente incentivo os leitores a examinFEdear não só os estudos citados explicitamente, mas também os muitos trabalhos adicionais referenciados por eles. Minha conscientização sobre as questões discutidas aqui foi provocada pelo trabalho em várias missões do Banco Mundial e durante uma visita estimulante ao Departamento de Pesquisa de Políticas do Banco Mundial durante 1995-1996, onde os colegas de equipe apresentaram perguntas desconcertantes que eu não estava preparado para responder. (Exemplo: Quais são as implicações macroeconômicas da descentralização fiscal?) Gostaria também de reconhecer o benefício de anos de discussão com acadêmicos na comunidade internacional da área de finanças públicas, muito numerosos para mencionar individualmente e, em qualquer caso, não ser responsável pelo conteúdo deste ensaio.

\section{REFERÊNCIAS}

ADES, Alberto F.; GLAESER, Edward L. Trade and circuses: explaining urban giants. The Quarterly Journal of Economics, v. 110, n. 1, p. 195227, 1995.

AHMAD, Junaid K. The Structure of Urban Governance in South African Cities. In: WILDASIN, David E. (Ed.). Fiscal aspects of evolving federations. Cambridge University Press, 1997. 
Administrative Office of the U.S. Courts. Bankruptcy Basics., Revised Second Edition. Washington, D.C., 2000 (2000a).

Annual Report of the Director. Washington, D.C., 2000 (2000b).

AUERBACH, Alan J.; KOTLIKOFF, Laurence J.; LEIBFRITZ, Willi. Introduction to" Generational Accounting around the World". In: Generational Accounting around the World. University of Chicago Press, 1999. p. 1-8.

BAHL, Roy. Comparative Federalism: Trends and Issues in the United States, China, and Russia. In: ROY, J. (Ed.) Macroeconomic Management and Fiscal Decentralization. Washington, D.C., 1995.

BAHL, Roy; WALLICH, Christine. Intergovernmental Fiscal Relations in China. World Bank Working Paper. The World Bank, 1992.

BARRO, Robert J. On the determination of the public debt. Journal of political Economy, v. 87, n. 5, Part 1, p. 940-971, 1979.

BIRD, Richard M.; EBEL, Robert D.; WALLICH, Christine I. Fiscal Decentralization: From Command to Market. In: BIRD, Richard M.; EBEL, Robert D.; WALLICH, Christine I. (Ed.). Decentralization of the socialist state: Intergovernmental finance in transition economies. The World Bank, 1995.

BOARD OF GOVERNORS OF THE FEDERAL RESERVE SYSTEM.

Flow of Funds Accounts of the United States: Flows and Outstandings, Third Quarter, 2003. Federal Reserve, 2004.

$\mathrm{BOHN}$, Henning. Budget balance through revenue or spending 
adjustments?: Some historical evidence for the United States. Journal of monetary economics, v. 27, n. 3, p. 333-359, 1991.

BOHN, Henning; INMAN, Robert P. Balanced-budget rules and public deficits: evidence from the US states. In: Carnegie-Rochester conference series on public policy. North-Holland, 1996. p. 13-76.

BORDIGNON, Massimo; MANASSE, Paolo; TABELLINI, Guido.

Optimal regional redistribution under asymmetric

information. American Economic Review, v. 91, n. 3, p. 709-723, 2001.

BOULDING, Kenneth E. Nelson, Richard R., and Sidney G. Winter. An

Evolutionary Theory of Economic Change. Cambridge: Harvard University Press, 1982.

BRENNAN, Geoffrey et al. The power to tax: Analytic foundations of a fiscal constitution. Cambridge University Press, 1980.

BRUCE, Neil. A fiscal federalism analysis of debt policies by sovereign regional governments. Canadian Journal of Economics, p. S195-S206, 1995.

BUCHANAN, James M. Federalism and fiscal equity. The American Economic Review, v. 40, n. 4, p. 583-599, 1950.

BUCKLEY, Robert M.; MINI, Federico. From commissars to mayors: cities in the transition economies. The World Bank, 2000.

BUCOVETSKY, Sam. Insurance and incentive effects of transfers among regions: equity and efficiency. International Tax and Public Finance, v. 4, n. 4, p. 463-483, 1997. 
BUETTNER, Thiess; WILDASIN, David E. The dynamics of municipal fiscal adjustment. No prelo, 2003.

COASE, Ronald H. The nature of the firm. economica, v. 4, n. 16, p. 386$405,1937$.

. The problem of social cost. In: Classic papers in natural

resource economics. Palgrave Macmillan, London, 1960. p. 87-137.

DILLINGER, William R.; WEBB, Steven Benjamin. Fiscal management in federal democracies: Argentina and Brazil. World Bank Publications, 1999.

DRAZEN, Allan. Political Economy in Macroeconomics. Princeton University Press, 2000.

EASTERLY, William. The Elusive Quest for Growth: Economists' Adventures and Misadventures in the Tropics. Cambridge: MIT Press, 2001.

EPPLE, Dennis; SCHIPPER, Katherine. Municipal pension funding: A theory and some evidence. Public Choice, v. 37, n. 1, p. 141-178, 1981.

GARCIA-MILÀ, Teresa; GOODSPEED, Timothy; MCGUIRE, Therese. Fiscal decentralization policies and sub-national government debt in evolving federations. 2002.

GENERAL ACCOUNTING OFFICE. Background Studies on Boston, Cleveland, New York, 1995.

HART, Oliver. Firms, Contracts, and Financial Structure. Oxford: Clarendon Press, 1995. 
VON HAGEN, Jürgen. A note on the empirical effectiveness of formal fiscal restraints. Journal of Public Economics, v. 44, n. 2, p. 199-210, 1991.

HAYEK, Friedrich August. The use of knowledge in society. The American economic review, v. 35, n. 4, p. 519-530, 1945.

HOLLOWAY, Gregory M. District Government: Information on its Fiscal Condition and the Authority's First Year of Operations. GAO report T-AIMD-96-126, Washington, 1996 (1996a).

. District Government: Information on its Fiscal Condition. GAO report T-AIMD-96-133, Washington, 1996 (1996b).

INMAN, Robert P. Transfers and bailouts: Enforcing local fiscal discipline with lessons from US federalism. Fiscal decentralization and the challenge of hard budget constraints, v. 35, p. 45-47, 2003.

JIN, Jing; ZOU, Heng-fu. Soft budget constraints and local government in China. Fiscal decentralization and the challenge of hard budget constraints, p. 289-322, 2003.

KOTLIKOFF, Lawrence J. Generational Accounting. New York: Free Press, 1992.

MARTINEZ-VAZQUEZ, Jorge; ALM, James. Public finance in developing and transitional countries. Edward Elgar Publishing Ltd, 2003.

MCCARTEN, William J. The challenge of fiscal discipline in the Indian 
states. Fiscal decentralization and the challenge of hard budget constraints, p. 249-286, 2003.

MELTZER, Allan H.; RICHARD, Scott F. A rational theory of the size of government. Journal of political Economy, v. 89, n. 5, p. 914-927, 1981.

NATIONAL BANKRUPTCY REVIEW COMMISSION et al. Bankruptcy, the Next Twenty Years: National Bankruptcy Review Commission Final Report. The Commission, 1997.

OATES, Wallace E. Toward a Second-Generation Theory of Fiscal Federalism. No prelo, 2004.

Fiscal Federalism. New York: Harcourt Brace Jovanovich, 1972.

OBSTFELD, Maurice; ROGOFF, Kenneth S.; WREN-LEWIS, Simon. Foundations of international macroeconomics. Cambridge: MIT Press, 1996.

OFFICE OF MANAGEMENT AND BUDGET. Analytical Perspectives: Budget of the United States Government, Fiscal Year 2005. Government Printing Office ,Washington, 2004 (2004a).

. Historical Statistics: Budget of the United States Government, Fiscal Year 2005. Government Printing Office, Washington, 2004 (2004b).

PERSSON, Torsten; TABELLINI, Guido. Political economics: explaining public policy. 2000.

DAHLBERG, Matz; PETTERSON-LIDBOM, Per. An empirical approach for evaluating soft budget constraints. Working Paper 28, Uppsala University, 2003. 
POTERBA, James M. State responses to fiscal crises: The effects of budgetary institutions and politics. Journal of political Economy, v. 102, n. 4, p. 799-821, 1994.

PRUD'HOMME, Remy. The dangers of decentralization. The world bank research observer, v. 10, n. 2, p. 201-220, 1995.

QIAN, Yingyi; WEINGAST, Barry R. China's transition to markets: market-preserving federalism, Chinese style. The Journal of Policy Reform, v. 1, n. 2, p. 149-185, 1996.

RAJAMARAN, Indira. A Fiscal Domain for Panchayats. Nova Déli: Oxford University Press, 2003.

RATTS, , Jørn. Studies in Fiscal Federalism and State-Local Finance. Cheltenham: Edward Elgar, 1998.

RODDEN, Jonathan A. Breaking the Golden Rule: Fiscal Behavior with Rational Bailout Expectations in the German States. No prelo, 2000.

RODDEN, Jonathan. Federalism and bailouts in Brazil. Fiscal decentralization and the challenge of hard budget constraints. Cambridge: MIT Press, 2003, p. 213-248.

SAIEGH, Sebastian M.; TOMMASI, Mariano. Why is Argentina's Fiscal Federalism so Inefficent? Entering the Labyrinth. CEDI Working Paper No. 11. Argentina: Centro de Estudios para el Desarrollo Institucional, 1998.

SEITZ, Helmut. Subnational Government Bailouts in Germany. ZEI Working Paper No. B20. Germany: ZE1 Center of European Integration 
Studies, 1999.

STRAUSS, Robert P. Does Pittsburgh Deserve PICA-West? Testemunho no Comitê de Finanças. Harrisburgh, 2003.

TANZI, Vito. Fiscal federalism and decentralization: A review of some efficiency and macroeconomic aspects. Washington: World Bank, 1995.

TER-MINASSIAN, Teresa. Borrowing by subnational governments: Issues and selected international experiences. International Monetary Fund, 1996.

TIROLE, Jean. Incomplete contracts: Where do we stand?. Econometrica, v. 67, n. 4, p. 741-781, 1999.

WEBB, Stephen B. Argentina: hardening the provincial budget constraint. Fiscal Decentralization and the Challenge of Hard Budget Constraints, p. 189-212, 2003.

WILDASIN, David E. The Economics of Urban Governance in South Africa. AF1EI Working Paper. Washington: World Bank, 1993.

. Externalities and bailouts: hard and soft budget constraints in intergovernmental fiscal relations. No prelo, 1997. . Local public finance in the aftermath of September 11. Journal of Urban Economics, v. 51, n. 2, p. 225-237, 2002. Fiscal competition in space and time. Journal of Public Economics, v. 87, n. 11, p. 2571-2588, 2003.

WORLD BANK. China: Macroeconomic Stability in a Decentralized 
Economy. Washington: World Bank, 1995.

AS INSTITUIÇÕES DO FEDERALISMO: COM RESPEITO A UM QUADRO ANALÍTICO

THE INSTITUTIONS OF FEDERALISM: TOWARD AN ANALYTICAL FRAMEWORK 